\title{
Can integrated geophysical investigations solve an archaeological problem? The case of the so-called Domus septem Parthorum in Rome (Italy)
}

\author{
Pier Matteo Barone ${ }^{1, *}$, Giorgia Carlucci ${ }^{2}$, Francesco Smriglio ${ }^{2}$, Francesco Basile ${ }^{2}$, \\ Giuseppe Della Monica ${ }^{2}$ \\ ${ }^{1}$ Archaeology and Classics Program, The American University of Rome, Via Pietro Roselli, 4 - 00153 Rome, Italy \\ ${ }^{2}$ Department of Science, University of Roma Tre, Via della Vasca Navale, 84 - 00146 Rome, Italy
}

\section{Email address:}

p.barone@aur.edu (P. M. Barone), giorgia.carlucci81@gmail.com (G. Carlucci), smriglio@ hotmail.it (F. Smriglio), basile@ fis.uniroma3.it (F. Basile), dellamonica@ fis.uniroma3.it (G. D. Monica)

\section{To cite this article:}

Pier Matteo Barone, Giorgia Carlucci, Francesco Smriglio, Francesco Basile, Giuseppe Della Monica. Can Integrated Geophysical Investigations Solve an Archaeological Problem? The Case of the So-Called Domus septem Parthorum in Rome (Italy). International Journal of Archaeology. Special Issue: Archaeological Sciences. Vol. 3, No. 1-1, 2015, pp. 21-25. doi: 10.11648/j.ija.s.2015030101.13

\begin{abstract}
Integrated geophysical prospecting has produced remarkable results in the field of archaeology. In addition to the recognition of archaeological sites, the evolution of a site can be reconstructed. Therefore, the combination of more than one geophysical technique can aid in understanding the layout of a site and help to answer interpretative questions. In this paper, we illustrate the use of two geophysical prospecting methods - ground-penetrating radar (GPR) and electrical resistivity tomography (ERT) - to interpret the archaeological site of the so-called Domus septem Parthorum in the center of Rome (Italy). The ability to investigate the subsurface at different horizontal and vertical resolutions demonstrates the advantage of using these two methods. The GPR provides high-resolution data on the upper remains in the shallow part of the soil, and the ERT detects deeper targets for a complete and exhaustive reconstruction of the buried anomalies. The results of this paper confirm the archaeological hypothesis that this so-called domus was repurposed as a house of worship during the Late Antiquity. In particular, the integrated geophysical acquisition supports the possible existence of a buried Paleochristian basilica.
\end{abstract}

Keywords: GPR, ERT, Archaeology, Integrated Investigations, Domus septem Parthorum, Late Antiquity

\section{Introduction}

The monumental complex that lies within the modern "Nando Martellini" athletic stadium in Rome, Italy, has been known as the Domus septem Parthorum (the House of the seven Parthians) since the end of the nineteenth century. The first phase of its construction served in part to support the slopes of the Aventine hill near the church of St. Balbina (Fig 1a). The earliest buildings date to the middle of the third century AD and consist of a large lily pond (nymphaeum) and an expansive rectangular hall. All that remains of the former is a thirty-meter-long apse. A large alcove lies at its center, flanked by three rows of smaller niches [1]. The nymphaeum was replenished with water from the Antonine aqueduct, which also supplied the baths of Caracalla. The row of corbels visible high on the wall of the hall would have supported a wooden balcony. During this period the complex was most likely used for public functions. Subsequently, towards the end of the third or the beginning of the fourth century $\mathrm{AD}$, the buildings were most likely converted to a bath complex. A barrel-vaulted room was built, as was a spiral staircase and a round room. The latter had a domed roof with an opening in the center. It was decorated with shells and fragments of pumice. Its construction obstructed one of the streams of spouting water that had flowed into the nymphaeum [2]. The fourth century AD saw the construction of an additional room with a tiled roof. All that remains is a large domed alcove inset with niches (Fig. 1b) and another small version. A fire sometime in the following century led to the abandonment of much of the complex. A roof was constructed over the original domed ceiling of the large apse. This could be interpreted as the conversion of the building to 
a place of worship during the Late Antiquity (fifth-sixth century AD), although no archaeological evidence (in particular, no pavement or complete walls) was found in the excavations made between 1986 and 1997 [1], and [2].

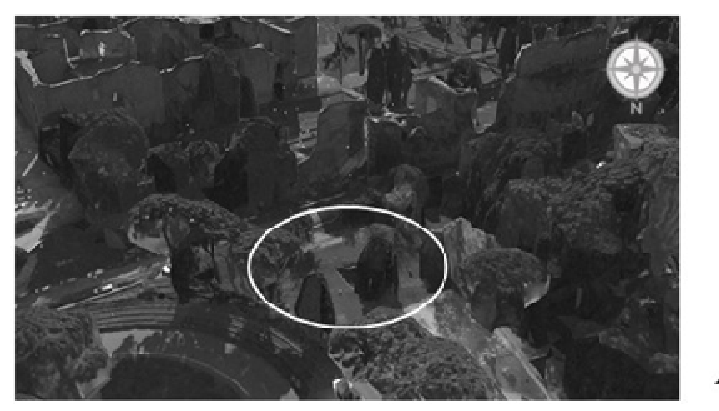

A

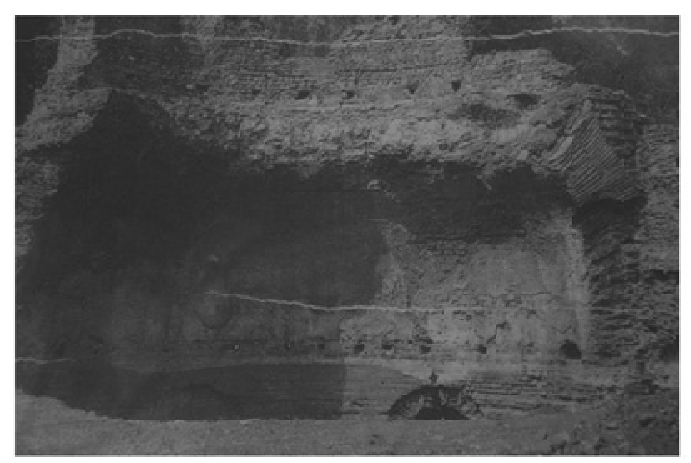

B

Figure 1. Fig. 1a illustrates the archaeological area of the so-called Domus septem Parthorum. In the western part, the slopes of the Aventine hill near the church of St. Balbina are visible. The remains of the fourth century AD large domed alcove are visible in fig. $1 b$.

Recently, certain preliminary geophysical investigations performed by the authors in agreement with the Sovraintendenza Capitolina ai Beni Culturali (Cultural Heritage Superintendence of Rome) observed the presence of several anomalies beneath the soil. Due to both the general and preliminary purpose of these investigations, as well as the interesting results, the authors decided to investigate this area more intensively.

As widely demonstrated in the literature [3] - [8], the joint analysis of different datasets and data integration in archaeology allow investigators to overcome the classic limitations imposed by the use of individual prospecting methods alone [9] - [11].

The primary aim of this new research is to understand the buried archaeological evidence partially explored by the 1986-1997 excavations. In particular, the research aims to better define the buried ancient structure with a high vertical and horizontal resolutions to highlight not only the shallow upper portion of the buried standing walls but also the level of the pavement, presumably at a depth of approximately 6 meters. For this reason, an integrated geophysical approach was necessary. The ground-penetrating radar (GPR) and electrical resistivity tomography (ERT) techniques are used to pinpoint the shallow and the deep anomalies, respectively.

\section{Methods, Data Acquisition, and Processing}

Due to their intrinsic characteristics, the combined use of the GPR and ERT techniques can delineate buried anomalies at different depths and at different resolutions. The GPR measurements are performed with the FINDAR system (Sensors \& Software, Inc.), equipped with $500 \mathrm{MHz}$ bistatic and non-separable antennas. A total of approximately 160 linear profiles were acquired during the investigations close to the large domed alcove. These profiles were divided among four grids (10x10 m, 10x6 m, 10x4 m, and 10x2.5 m), with an interline space of $0.5 \mathrm{~m}$ in both $\mathrm{X}$ and $\mathrm{Y}$ directions, according to the possible dimension of the targets and to the presence of different modern obstacles, such as a metallic fence and a long-jump track (Fig. 2a). The grids were georeferenced using a commercial GPS.

The GPR system was able to collect high-quality data that did not require specific filtering or signal recovery processing. To identify the buried targets, each radar section was analyzed by applying the basic dewow time filter and automatic gain control.

To convert the two-way travel time into depth, a velocity analysis was performed using the so-called "hyperbola calibration" technique [12] on all GPR sections in which hyperbolic events were well detected. This analysis showed the presence of a quite dry soil and provided an average velocity of $0.12 \pm 0.01 \mathrm{~m} / \mathrm{ns}$. Due to this velocity, it is worth noting that the hyperbolic anomalies in all 4 grids are located at a depth of $1-1.3 \mathrm{~m}$.

To better define the geometry of the buried remains, the grid data were interpolated, and a series of migrated depth-slice maps were generated by applying the average envelope amplitude algorithm to each trace [13]. Finally, using the computed average signal velocity, the migration process is used to estimate the target depths.

The ERT measurements were performed using a georesistivimeter 16SG model (Pasi, S.r.l.), equipped with 64 electrodes with a spacing of $1 \mathrm{~m}$. As conventionally reported in literature, e.g., [14] and [15], the depth of investigation is up to $1 / 5$ or $1 / 6$ of the total length of the electrical profile. Three ER tomographies were collected in the archaeological area of the so-called Domus septem Parthorum, partially overlapping the GPR measurements. In particular, the Wenner-Schlumberger configuration is used in two ERT profiles (tomographic profiles 1 and 2 in Fig. 2b), and the Dipole-Dipole configuration is used in the third one (tomographic profile 3 in Fig. 2b). These two methods are used because the Wenner-Schlumberger method provides data on the upper part of the structures, whereas the Dipole-Dipole method provides better vertical data on the structures. 


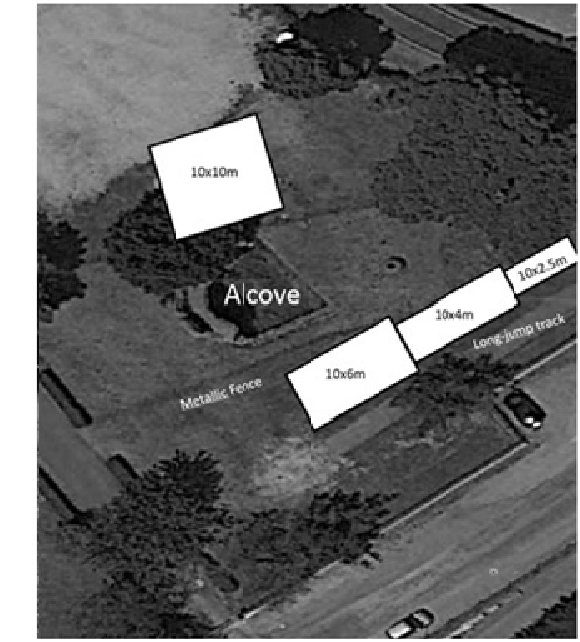

A

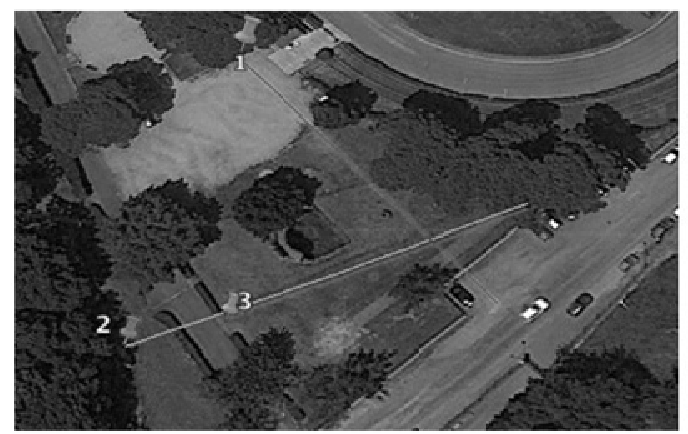

B

Figure 2. In this figure, the locations of the 4 GPR grids (a) and the three ERT profiles (b) are visible. Note that tomographic profiles 1 and 2 are 64-m long, whereas tomographic profile 3 is 48-m long.

The first part of the third profile was not adequately energized; thus, this profile starts at $16 \mathrm{~m}$. The measurement of electrical resistivity is performed using configurations based on a quadrupole pattern. The aim of the ERT technique is, basically, to reconstruct the best shape, position and real resistivity of the different lithologies and any buried structures from numerous measurements of apparent resistivity, which depends on the number of electrodes arranged on the ground and on the type of quadrupole [16]. The measurements and interpretation of apparent resistivity are produced thanks to the inversion technique involving the simultaneous use of both modeling finite-element (or finite-difference) algorithms and optimization least-squares methodologies [10], [17], and [18]. Therefore, the iteration of the resolution procedure allows us to estimate the distribution of resistivity in the investigated medium, producing an intuitive and effective graphical image [19].

\section{Results and Interpretation}

As previously mentioned, the four grids are arranged close to the large domed alcove shown in fig. 1c. The radargrams presented in Fig. 3a show several hyperbolic anomalies, which are also consistently detected at the same depth and approximately in the same position in each grid. These anomalies, shown in the GPR maps in Fig. 3b, align along orthogonal directions and have the typical geometry of perimeter walls of a building. The depth of the top of these structures is between 1.0 and $1.3 \mathrm{~m}$. The position and geometry of these structures (i.e., the large rectangular feature with two $90^{\circ}$ angles), are in agreement with the visible semi-circular archaeological structure (i.e., the alcove). During the geophysical investigations, in the area of the 10x10 $m$ GPR grid, it was possible to identify a crop mark on the grassy surface indicative of the presence of a buried solid structure with a $90^{\circ}$ angle (fig. 4).

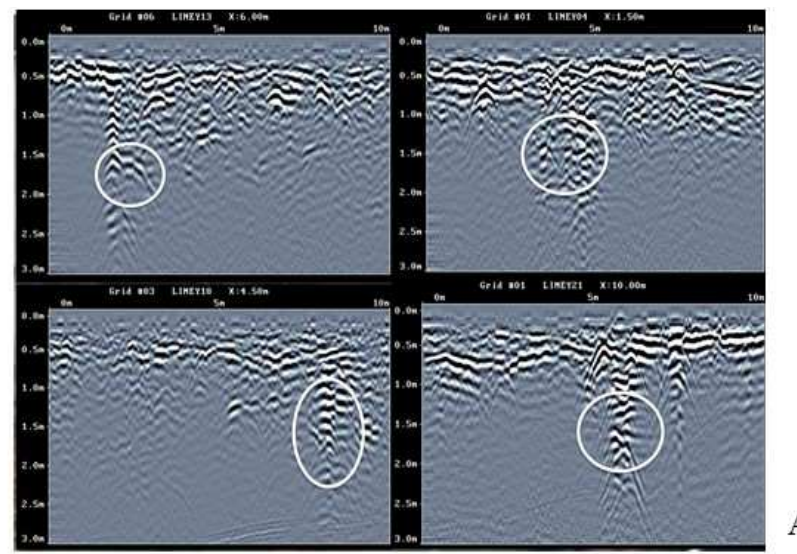

A

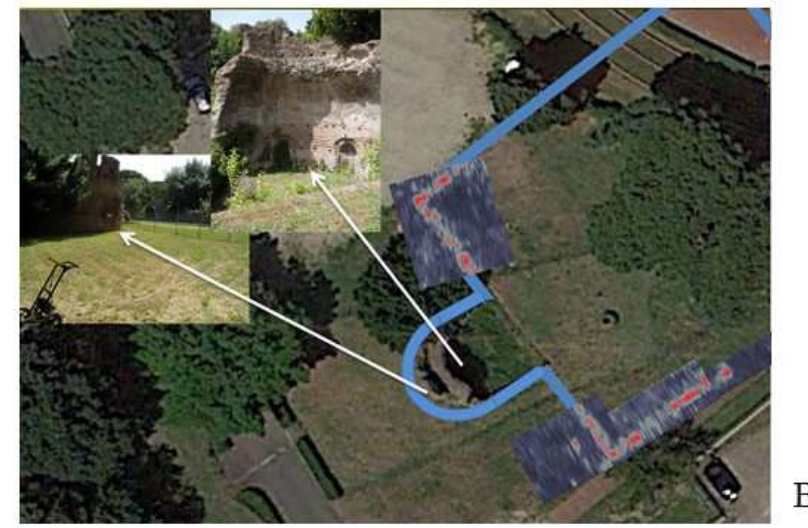

Figure 3. Fig. 3a shows the radargrams with several hyperbolic anomalies detected at the same depth (between 1.0 and $1.3 \mathrm{~m}$ ) and approximately in the same position for each grid. The GPR maps in fig. $3 b$ illustrate a large rectangular feature (in blue) in agreement with the visible semi-circular archaeological structure (i.e., the alcove).

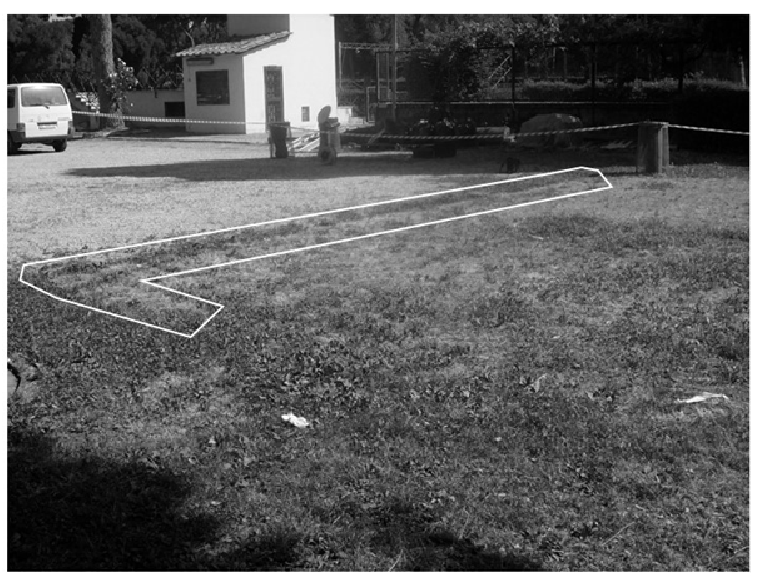

Figure 4. In this figure, it is possible to identify a crop mark on the grassy surface, indicating the presence of a buried solid structure with a $90^{\circ}$ angle in the area of the $10 \times 10 \mathrm{~m}$ GPR grid. 
Fig. 5a (tomographic profile 1 in Fig. 2b) shows the results of the Wenner-Schlumberger method, which reaches a depth of approximately $7.5 \mathrm{~m}$. The most interesting element is the high-resistivity area underlying the entire profile. Starting from $6 \mathrm{~m}$ depth, there is a clear area with resistivity values of approximately $200-300 \mathrm{ohm} / \mathrm{m}$. Based on the position of the buried shallow anomalies detected by the GPR, this high-resistivity zone appears to be a flat manmade structure, most likely related to a buried floor level.

The other two tomographic profiles (Figs. 5b and c) share the same profile but were collected using different methods Wenner-Schlumberger in fig. $5 b$ (tomographic profile 2 in fig. 2b), and Dipole-Dipole in fig. 5c (tomographic profile 3 in Fig. $2 b)$. Both results show areas of high resistivity at the same location along the profile and at the same depth (approximately 1-1.5 $\mathrm{m}$ ). The measured values are approximately $200 \mathrm{ohm} / \mathrm{m}$, which are likely related to a masonry building. In this case, the manmade structures are vertical walls in perfect agreement with the results already highlighted by the GPR 10x6 grid (i.e., the buried $90^{\circ}$ angle).
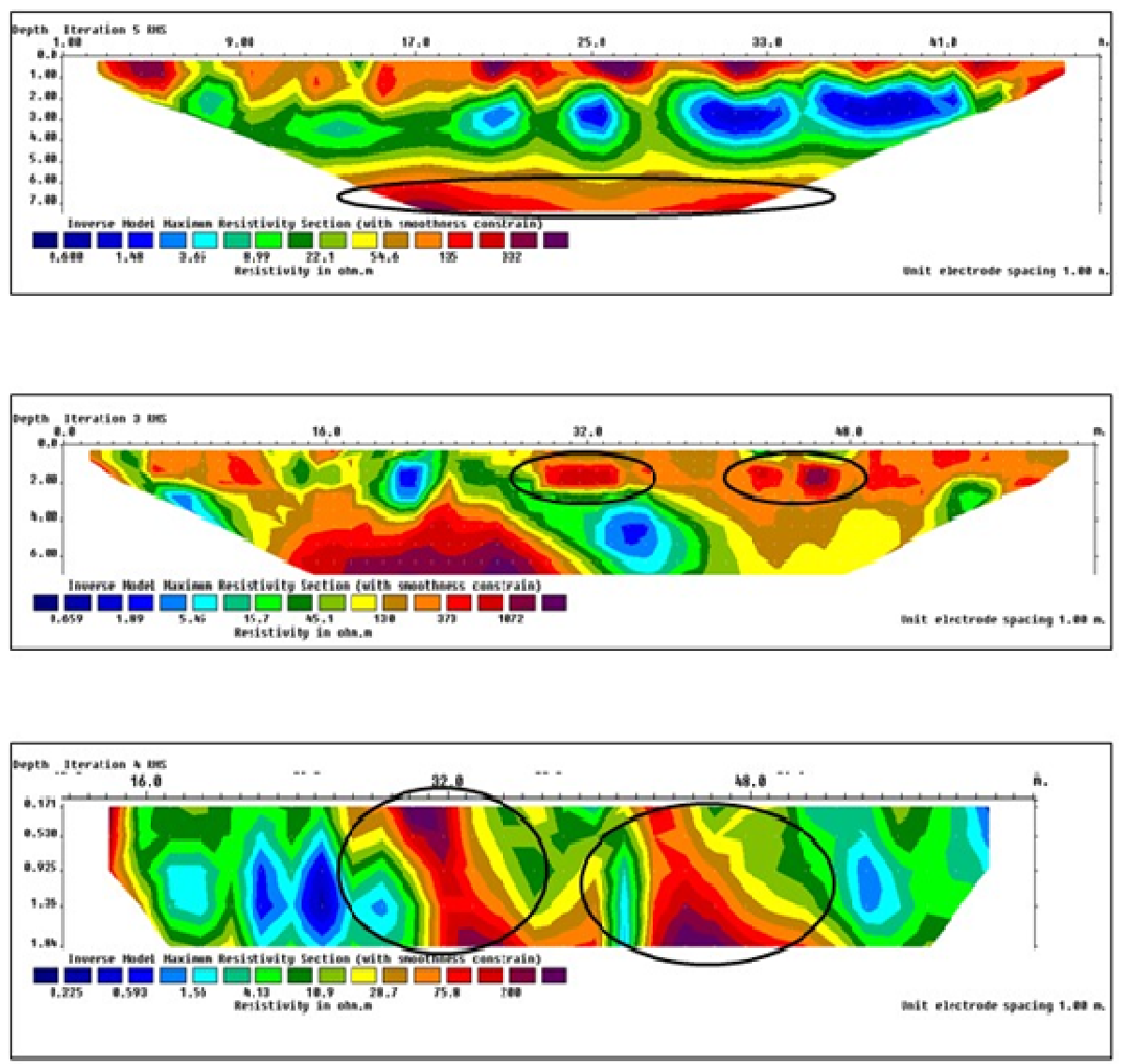

Figure 5. In fig. 5a, the ERT result highlights the presence of a high-resistivity, elongated area at a depth of $6 \mathrm{~m}$ (black circle), likely related to a floor level. Figs. $5 b$ (Wenner-Schlumberger) and $5 c$ (Dipole-Dipole) illustrate the high-resistivity anomalies related to the presence of buried wall structures (black circles).

The integrated GPR and ERT data enable the complete reconstruction of a partially unknown archaeological area of Rome. The archaeological excavations were unable to obtain sufficient results to confirm the hypothesis that the pre-existing, semi-abandoned building was repurposed as a place of worship during the Late Antiquity. However, the presence of both a rectangular structure with an apse and the deeper pavement suggest the construction of a small Paleochristian church (a so-called basilica). Fig. 6 shows a reconstruction of the possible geometry of such a typical ancient religious building.

Unfortunately, the presence of the modern athletic stadium limits the ability to detect the entire structure. However, supplementary integrated geophysical investigations can help us better understand the area outside the basilica.

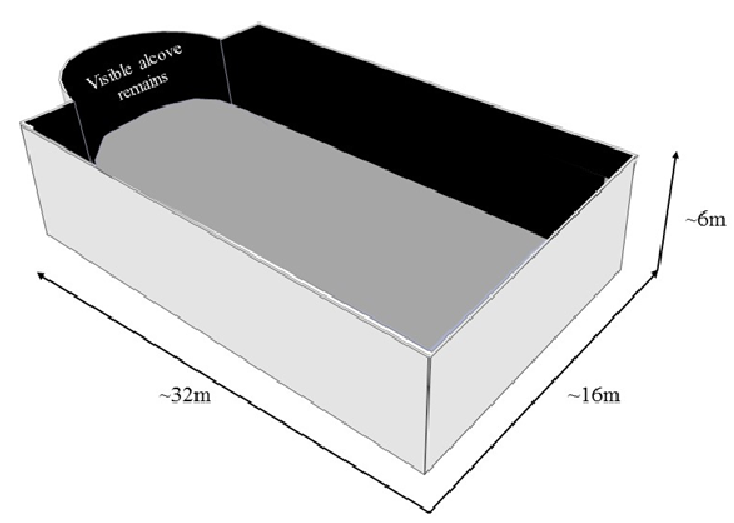

Figure 6. Possible reconstruction of the buried structure detected by the integrated geophysical methods. The shape can be interpreted as a Paleochristian basilica. 


\section{Conclusions}

The choice of technique to be used in the search for buried archaeological structures depends very much on the particular situation and on the different landscapes that have to be surveyed. Integrated geophysical prospecting for archaeological features not only delivers detailed maps of buried structures but also solves certain archaeological interpretive problems.

The multi-approach results from the archaeological site of the so-called Domus septem Parthorum demonstrate how two different geophysical techniques with different characteristics can be combined to obtain a clear reconstruction of the shape of buried ruins. The anomalies are confirmed to be related to a Late Antiquity religious building (i.e., a Paleochristian basilica) with a rectangular geometry, an apse and a paved floor. Taking into consideration the several reuses of the area over the centuries, including the recent construction of a modern athletic stadium, the acquisition of important integrated archaeological datasets is essential to obtaining both a coherent answer to a historical interpretive problem and a coherent idea of the urban evolution in the past.

\section{Acknowledgements}

We are grateful to Dr. Maria Letizia Buonfiglio and Dr. Monica Ceci of the Sovraintendenza Capitolina ai Beni Culturali for their support.

\section{References}

[1] D. Mancioli, A. Ceccarelli, and R. Santangeli-Valenzani, Domus Parthorum, Archeologia Laziale, 11, 1993, pp. 55-58.

[2] C. Taffetani, Il complesso della c.d. Domus Parthorum. Nuova interpretazione delle fasi costruttive, in $\mathrm{D}$. Manacorda and $\mathrm{R}$. Santangeli Valenzani (eds), Roma il primo miglio della via Appia, Croma Ed., 2010, pp. 39-46.

[3] M. Moscatelli, S. Piscitelli, S. Piro, F. Stigliano, A. Giocoli, D. Zamuner, and F. Marconi, Integrated geological and geophysical investigations to characterize the anthropic layer of the Palatine hill and Roman Forum (Rome, Italy), Bulletin of Earthquake Engineering, 12, 3, 2014, pp. 1319-1338. DOI: 10.1007/s10518-013-9460-5K.

[4] P. Rodríguez-Gonzálvez, A. Muñoz-Nieto, I. Gozalo-Sanz, J. Mancera-Taboada, D. González-Aguilera, and P. Carrasco-Morillo, Geomatics and Geophysics Synergies to Evaluate Underground Wine Cellars, International Journal of Architectural Heritage: Conservation, Analysis, and Restoration, 8, 4, 2014, pp. 537-555. DOI:10.1080/15583058.2012.702370
[5] L. Nuzzo, G. Leucci. and S. Negri, GPR, ERT and magnetic investigations inside the Martyrium of St Philip, Hierapolis, Turkey, Archaeological prospection, 16, 3, 2009, pp. 177-192. DOI: $10.1002 / \operatorname{arp} .364$

[6] E. Forte, M. Pipan, and M. Sugan, Integrated Geophysical Study of Archaeological Sites in the Aquileia Area, CEUR Workshop Proceedings, 806, 2011, pp. E1-E11.

[7] S. Negri, G. Leucci, and F. Mazzone, High resolution 3D ERT to help GPR data interpretation for researching archaeological items in a geologically complex subsurface, Journal of Applied Geophysics, 65, 2008, pp. 111-120.

[8] N.G. Papadopoulos, A. Sarris, W.A. Parkinson, A. Gyucha, R.W. Yerkes, P.R. Duffy, and P. Tsourlos, Electrical Resistivity Tomography for the Modelling of Cultural Deposits and Geomophological Landscapes at Neolithic Sites: a Case Study from Southeastern Hungary, Archaeological Prospection, 2014, Early view. DOI: $10.1002 / \operatorname{arp} .1480$

[9] A. Witten, Handbook of Geophysics in Archaeology, Equinox Publishing, 2006, Oxford.

[10] J.J. Milsom, and A. Eriksen, Field Geophysics, Wiley-Blackwell, 2011.

[11] M.E. Everett, Near-Surface Applied Geophysics, Cambridge University Press, 2013.

[12] A.P. Annan, Ground Penetrating Radar: principles, procedures \& applications, Sensors \& Software, Inc, 2004, technical paper.

[13] A.P. Annan, Practical processing of the GPR data, Sensors \& Software, Inc, 1999, technical paper.

[14] M.H. Loke, Electrical imaging surveys for environmental and engineering studies. A practical guide to 2-D and 3-D surveys, 1997, Penang, Malaysia.

[15] M.H. Loke Time-lapse resistivity imaging inversion, Proceedings of the $5^{\text {th }}$ Meeting of Environmental and Engineering Geophysical Society, European Section, 1999, Em1.

[16] W.M. Telford, L.P. Geldart, and R.E. Sheriff, Applied Geophysics, Cambridge University Press, 1990.

[17] C.C. Pain, J.V. Herwanger, M.H. Worthington, and C.R.E. De Oliveira, Effective multidimensional resistivity inversion using finite-element techniques, Geophysical Journal International, 151, 2002, pp. 710-728. DOI:10.1046/j.1365-246X.2002.01786.x

[18] O. Zienkiewicz, and R. Taylor, Finite Element Method: Solid and Fluid Mechanics Dynamics and Non-Linearity, $4^{\text {th }}$ ed., Vol. 2, 1991, McGraw-Hill, New York.

[19] A. Samouëlian, I. Cousin, A. Tabbagh, A. Bruand, and G. Richard, Electrical resistivity survey in soil science: a review, Soil \& Tillage Research, 83, 2005, pp. 173-193. DOI: 10.1016/j.still.2004.10.004 